\title{
Probabilistic seismic hazard assessment of NW and central Himalayas and the adjoining region
}

\author{
Madan Mohan Rout*, Josodhir Das, Kamal and Ranjit Das \\ Department of Earthquake Engineering and CoEDMM, Indian Institute of Technology Roorkee, \\ Roorkee, Uttarakhand 247667 , India. \\ *Corresponding author.e-mail: madaniitr@gmail.com
}

\begin{abstract}
The Himalayan region has undergone significant development and to ensure safe and secure progress in such a seismically vulnerable region there is a need for hazard assessment. For seismic hazard assessment, it is important to assess the quality, consistency, and homogeneity of the seismicity data collected from different sources. In the present study, an improved magnitude conversion technique has been used to convert different magnitude scales to moment magnitude scale. The study area and its adjoining region have been divided into 22 seismogenic zones based upon the geology, tectonics, and seismicity including source mechanism relevant to the region. Region specific attenuation equations have been used for seismic hazard assessment. Standard procedure for PSHA has been adopted for this study and peak ground motion is estimated for $10 \%$ and $2 \%$ probability of exceedance in 50 years at the bed rock level. For the $10 \%$ and $2 \%$ probability of exceedance in 50 years, the PGA values vary from 0.06 to $0.36 \mathrm{~g}$ and 0.11 to $0.65 \mathrm{~g}$, respectively considering varying $b$-value. Higher PGA values are observed in the southeast part region situated around Kaurik Fault System (KFS) and western parts of Nepal.
\end{abstract}

\section{Introduction}

The Himalayan region remains one of the most seismically active regions of the world. Due to continued collision of India with the Eurasian plate, strain energy is progressively accumulating in the Himalayas and this energy gets released from time to time in the form of earthquakes. In view of ongoing seismic activities, the region has been assigned as seismic zones IV and V in the seismic hazard zonation map of India (BIS 2002). In the last two centuries, the Himalayan region has experienced many great earthquakes $(M \geq 8)$, notable among these are the Shillong Earthquake of 1897 $(\mathrm{M}=8.7)$, the Kangra Earthquake of $1905(\mathrm{M}=8.0)$, the Bihar-Nepal Earthquake of $1934(\mathrm{M}=8.3)$ and the Assam Earthquake of $1950(\mathrm{M}=8.5)$. It is important to carry out seismic hazard analysis of the region because of its high level of natural seismicity and the presence of segments of major longitudinal tectonic boundary thrusts, namely the Main Central Trust (MCT) and the Main Boundary Thrust (MBT) along with various neotectonic faults traversing through the areas. Several authors have attempted to estimate PSHA for the Indian subcontinent and for different parts of the country (e.g., Khattri et al. 1984; Bhatia et al. 1999; Mahajan et al. 2010; Nath and Thingbaijam 2012; Patil et al. 2014). Bhatia et al. (1999) estimated expected PGA for the Himalayan region between 0.10 and $0.30 \mathrm{~g}$ with $10 \%$ probability of exceedance in 50 years. These values were obtained under Global Seismic Hazard Assessment Programme (GSHAP). Recently National Disaster Management Authority (NDMA 2011), Government of India, presented various probabilistic seismic

Keywords. Northwest Himalaya; seismicity; PSHA; seismogenic zones; PGA. 
hazard maps showing the ground motion parameters for different return periods for the whole country. For seismic hazard assessment, the first step is to identify the seismogenic zones and then the seismicity parameters for all seismogenic zones. Mahajan et al. (2010) delineated 16 rectangular seismogenic zones and three line seismogenic zones for NW Himalaya and Gupta (2006) delineated seismogenic zones in India by analyzing the seismotectonic characteristics.

All the previous studies are either based on inappropriately homogenized earthquake catalogs or heterogeneous catalogs with old attenuation equations. We delineate 22 seismogenic zones considering the tectonics, seismicity, and focal mechanism. In the region, various magnitude scale conversion techniques and different attenuation equations for seismic hazard assessment have been used by different authors. Present study is based on an earthquake catalog, which is prepared using an improved magnitude conversion technique towards $\mathrm{M}_{\mathrm{w}}$ (moment magnitude) estimation (Das et al. 2012a, b, 2013; Wason et al. 2012). Different ground motion prediction equations have been used to calculate the probabilistic seismic hazard map of NW and central Himalayan region using Cornell (1968) approach.

The predicted ground motion hazard in this work takes care of different parameters for seismogenic zone delineations, advanced empirical relations for magnitude conversion, and suitable ground motion prediction equations. For the return period of 475 years, the maximum ground motion hazard of $0.36 \mathrm{~g}$ estimated in this work was found to be in agreement with the recommended ground motion in seismic hazard zonation map of India. The information from seismic hazard analysis of the NW and central Himalayas will be helpful to plan and take some preventive steps to reduce casualties and economical losses likely to occur from earthquake disasters in particular.

\section{Seismotectonics of the NW and central Himalaya}

The NW and central Himalayas and the adjoining region are associated with the underthrusting of rock blocks resting on the Indian plate resulting into development of two regionally northerly dipping convergent zones; the MCT and MBT. The MBT is a series of thrusts that separates the lesser Himalaya from the sub-Himalaya belt (Valdiya 1980). The MCT at the base of the central crystalline zone dips northward separating the Higher Himalaya from the Lesser Himalayas (Gansser 1977) and it may be noticed that the MCT is terminated against transverse Kishtwar Fault (KF) in Jammu and Kashmir. On the north side of the MCT, three prominent tectonic features, viz., Bangong-Nujiang Suture (BNS), Indus suture zone (ISZ), and Karakoram Fault (KKF) cut across the region. The ISZ marks the boundary between the Indian and Tibetian plates. The

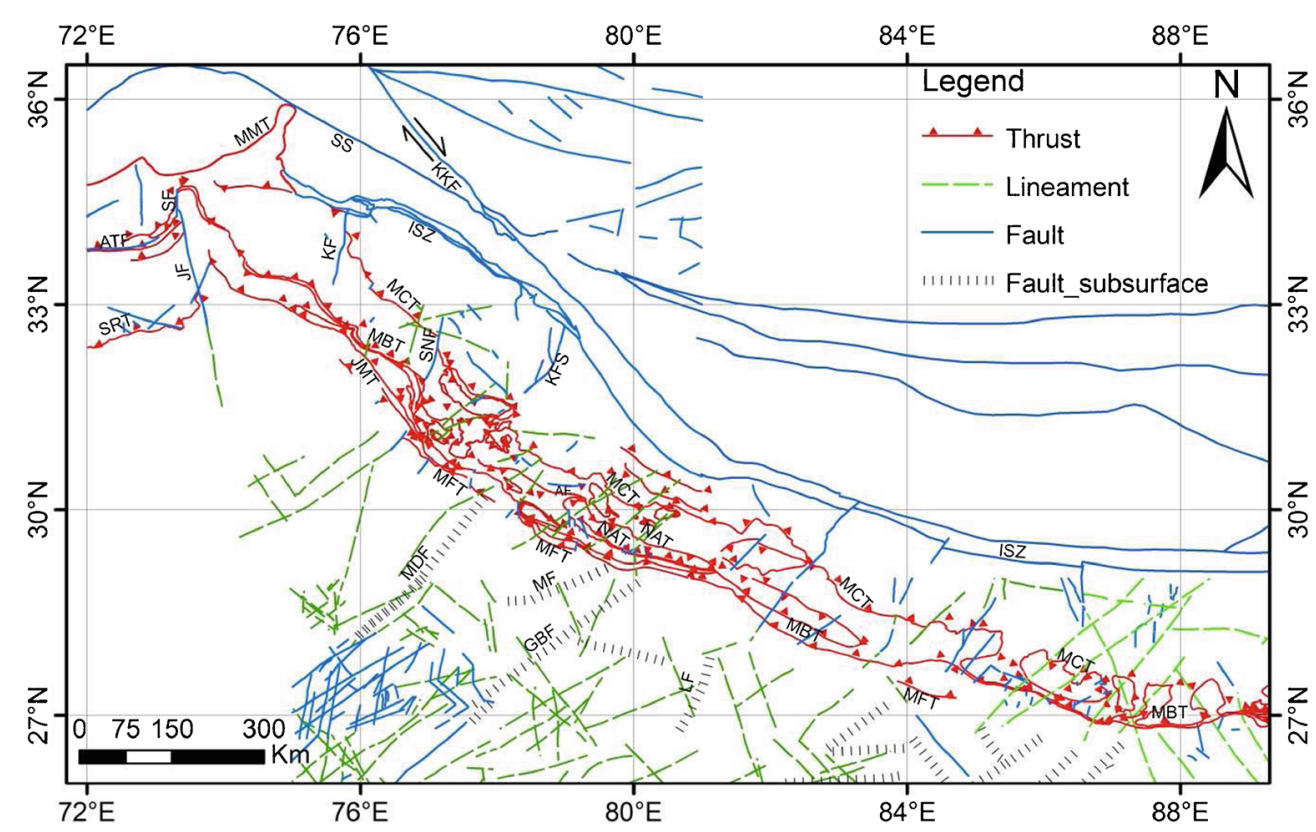

Figure 1. Tectonic features present in and around NW and central Himalayas. KKF: Karakoram Fault, SS: Shyoke Suture, MMT: Main Mantle Thrust, SRT: Salt Range Thrust, ATF: Attok Fault, MCT: Main Central Thrust, MBT: Main Boundary Thrust, ISZ: Indus Suture Zone, KFS: Kaurik Fault System, AF: Alaknanda Fault, NAT: North Almora Thrust, JMT: Jwalamukhi Thrust, MFT: Main Frontal Thrust, JF: Jhelum Fault, SK: Sinkiari Fault, KF: Kishtwar Fault, SNF: Sunder Nagar Fault, MDF: Mahendragarh-Dehradun Fault, MF: Moradabad Fault, GBF: Great Boundary Fault, LF: Lucknow Fault, MFT: Main Frontal Thrust (tectonic features are adopted from GSI 2000). 
very extensive Karakoram Fault (KKF) is the most prominent tectonic feature present in the region. One of the most important transverse faults in the western Himalaya is the Sundernagar Fault (SNF) also called Manali Fault which is dextral in nature and traverses extending from Higher Himalaya to Frontal Belt. To the east of SNF is another important transverse feature Kaurik Fault System (KFS). The KFS of higher Himalaya is characterised by normal faulting exhibiting splays that might have ruptured recently during Kinnaur Earthquake of 1975 (GSI 2000). Among longitudinal faults, the E-W trending Alaknanda Fault $(\mathrm{AF})$ is one of the most conspicuous one. The subsurface Mahendragarh-Dehradun Fault (MDF), Moradabad Fault (MF), and Great Boundary Fault (GBF) are also important structural elements recognised in the Gangetic foredeep. Figure 1 shows the tectonic features of the region.

The seismic activity of the western and central Himalayas is closely associated with the active faults and the regional tectonic features. The region has experienced several earthquakes of moderateto-large magnitudes in the last two centuries. Among these, Kangra Earthquake of 1905 (M=8.0) and Kashmir Earthquake of $2005 \quad\left(\mathrm{M}_{\mathrm{w}}=7.6\right)$ are large earthquakes, whereas 1945 Chamba Earthquake $\left(\mathrm{m}_{\mathrm{b}}=6.5\right), 1986$ Dharamshala Earthquake $\left(\mathrm{m}_{\mathrm{b}}=5.5\right)$, Kinnaur Earthquake $\left(\mathrm{m}_{\mathrm{b}}=6.5\right)$ of 1975,1991 Uttarkashi Earthquake $\left(\mathrm{m}_{\mathrm{b}}=6.4\right)$, and Chamoli Earthquake of $1999\left(\mathrm{~m}_{\mathrm{b}}=6.8\right)$ are moderate earthquakes. Most of the earthquakes in this region are of shallow focus (0-40 km depth) and few have depth in the range between 41 and $255 \mathrm{~km}$.

\section{Delineation of seismogenic zones}

For the purpose of delineation of seismogenic zones, spatial occurrences of earthquakes and various tectonic features have been carefully scrutinized. It is evident that the regional tectonic features follow the main Himalayan structural belt. However, the convergent tectonics of the Himalayan region got manifested through discrete Main Frontal Thrust, the feature developing in the adjoining regions south of the Himalayan foothills. Further, earthquakes (viz., 1934, 1988 Bihar-Nepal Earthquake) also have occurred far south of the Himalayan orogenic belt. In view of this, the adjoining parts occurring south of Himalayan mountain belt assume tectonic significance having earthquake potential. Similarly, areas of trans-Himalayas and southern Tibet are to be considered tectonically significant in view of their vicinity to the main orogenic belt. Considering the above facts, adjoining regions of the main Himalayan belt have also been considered to be included as seismic zones in this study. Based upon the seismicity, tectonics and earthquake dynamic processes, the region has been divided into 22 seismogenic zones. The delineated siesmogenic zones along with seismicity and tectonic features are shown in figure 2 .

Seismogenic zone 1 includes an area affected by Main Mantle Thrust (MMT) that resulted due to collision of the Asian plate and Kohistan, wherein the rocks of the Asian plate were thrust over the Kohistan (GSI 2000). The seismogenic zones 2 and 3 are mainly comprised of a northeastwardly trending fold belt and north-northwestwardly transverse fault occurring in an area west of the Himalayan fold belt. The seismogenic zones 4, 6, 7, 8, 10, 11, 13, 15, 16, 19 and 20 constitute Himalayan structural belt covering Jammu and Kashmir, Himachal Pradesh, Uttarakhand, Nepal and Sikkim. The structural trend of the Himalayas in the western part is mostly NW-SE which swings to eastsoutheasterly in Uttarakhand to easterly in Nepal. Prominent regional tectonic features of this zone are Main Central Thrust (MCT), Main Boundary Thrust (MBT), and discrete Main Frontal Thrust (MFT) dissecting and dividing the whole belt longitudinally. This belt is also affected by transverse faults, viz., Sundernagar Fault (SNF) and Kistwar Fault (KF). SNF displaces MCT transversely for considerable distance; however, it may be seen that the MCT terminates against KF (GSI 2000). In the area between the SNF and KF and north of MBT very high concentration of earthquake occurrence is reported indicating intense tectonic activity in the region. Figure 2 shows the seismogenic zones along with the seismicity.

In the Uttarakhand region, the prominent tectonic features besides MCT and MBT are longitudinal E-W trending Alaknanda Fault (AF), Martoli Thrust (MT), southward dipping North Almora Thrust (NAT), South Almora Thrust (SAT), and Ramgarh Thrust (RT). This structural belt has undergone different stages of crustal evolution and has been subjected to orogenic movements of varying intensity from time to time (GSI 2000). Many significant earthquake clusters occur in this zone. Earthquake clusters are located north of MBT and spread across the MCT indicating the area between MBT and MCT and north of MCT is active. The seismogenic zone 10 encompasses neotectonic Kaurik Fault System (KFS) defined by number of half-graben faults and is active as it is considered that rupturing along the fault system had triggered Kinnaur Earthquake of 1975 (GSI 2000). Further eastward, the Himalayan belt continues within Nepal with similar features.

Seismogenic zones 9, 17, 18, 21, 22 are characterized by trans-Himalayan region north of the central crystalline belt. This zone is marked by extensive 


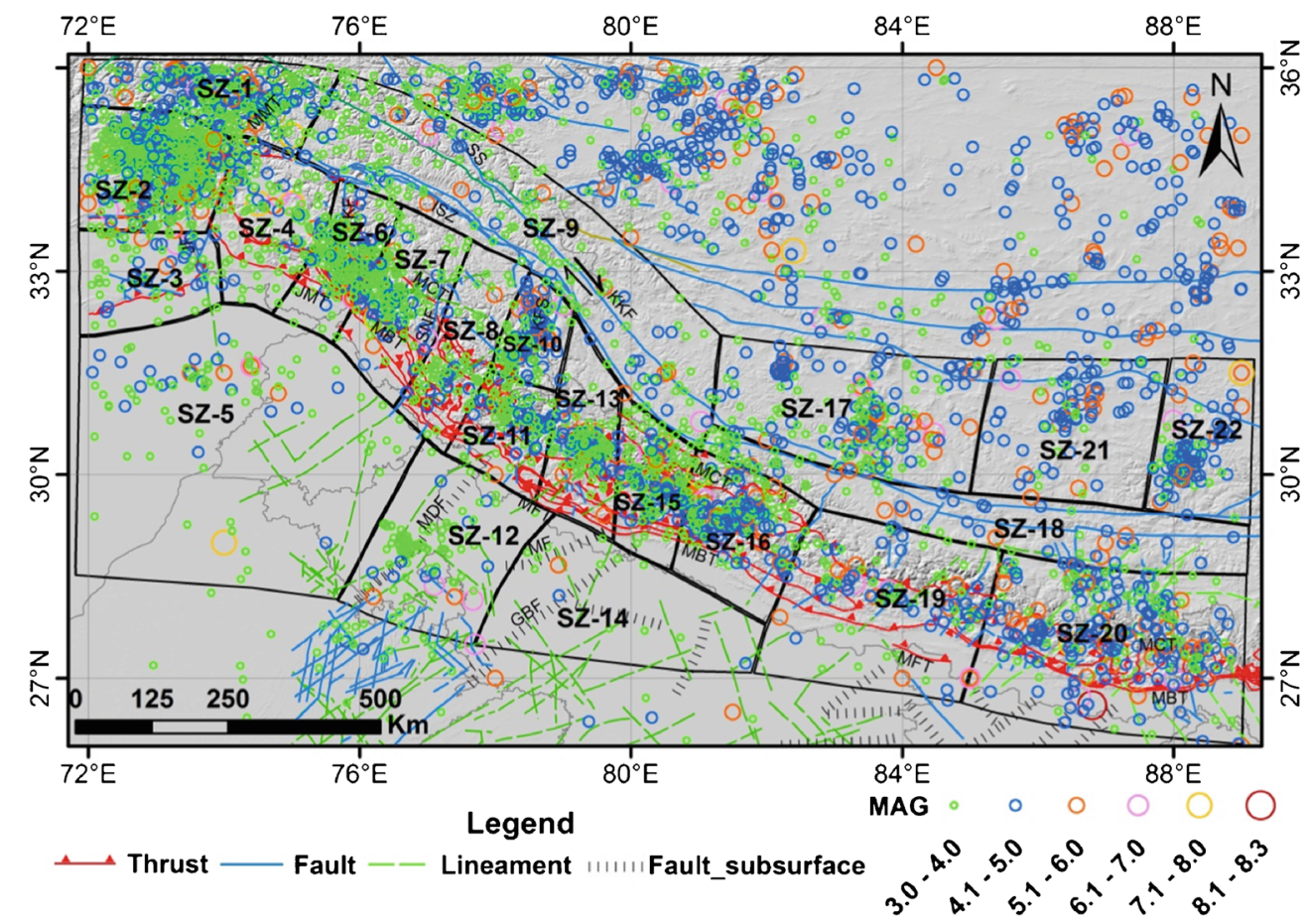

Figure 2. Demarcation of seismogenic zones based on geology, tectonics and seismicity. MMT: Main Mantle Thrust, MCT: Main Central Thrust, MBT: Main Boundary Thrust, KKF: Karakoram Fault, ISZ: Indus Suture Zone, KFS: Kaurik Fault System, NAT: North Almora Thrust, KF: Kishtwar Fault, SNF: Sunder Nagar Fault, MDF: Mahendragarh-Dehradun Fault, MF: Moradabad Fault, GBF: Great Boundary Fault, MFT: Main Frontal Thrust.

ISZ, Karakoram Fault (KKF), and Shyok Suture (SS). ISZ marks the boundary between the Indian and Tibetan plates and south of this, litho-units of the main Himalayan belt are exposed and traverse across the study area from west to east. KKF is the most extensive tectonic feature present in the region, which has affected the region with a huge dextral offset and is traceable towards northwest through the Shyok Suture to the Pamir. This fault extends for almost $1000 \mathrm{~km}$ from central Pamir to Kumaon Himalayas (GSI 2000). The seismic zones 17, 21, and 22 occupy areas of southernmost Tibetan Plateau.

Seismogenic zones 5, 12, and 14 cover areas of foothills and northern part of Ganges plains. Zone 5 forms westernmost part of Indo-Gangetic basin covering parts of Punjab and Haryana. This zone is filled with alluvium and marked by a few NE-SW and NW-SE trending lineaments. The prominent tectonic feature of zone 12 is the NNE trending subsurface Mahendragarh Dehradun Fault (MDF), which extends northeastward up to the Himalayan foothills. The Delhi-Haridwar ridge is aligned with the MDF and is considered to be prolongation of the NNE-SSW directed peninsular rock (Aravalli) as a horst delimited by faults (GSI 2000). This zone has been affected by numerous earthquakes. The zone 14 is occupied by the Delhi-Moradabad province wherein the Neogene sediments directly overlie the Delhi basement. The Moradabad fault zone forms the eastern boundary of the DelhiMoradabad tectonic province. This NE-SW trending tectonic feature is traceable on to the shield area as a tectonic boundary between the Delhi folded belt and the Vindhyans. This seismic zone is marked by subsurface faults namely Moradabad Fault (MF) and Great Boundary Fault (GBF) and a few lineaments. These faults have NE-SW trends and configures the basement tectonics.

\section{Homogenization of earthquake catalog}

The details about earthquakes that occurred in the past are obtained from various agencies. In this study, earthquake data compiled from three agencies: International Seismological Center (ISC), UK catalog of seismic events from 1720-1972, National Earthquake Information Center (NEIC), USGS, USA catalog of seismic events from 1973-2011 and India Meteorological Department (IMD) catalog of seismic events from 1552-2011 have been used. In addition to global catalogs, some local catalogs prepared by Oldham (1883) and Iyengar et al. (1999) are also considered.

The preparation of a homogenous earthquake catalog for a seismic region needs regressed relations for conversion of different magnitude types, e.g., $\mathrm{m}_{\mathrm{b}}, \mathrm{M}_{\mathrm{s}}$, to the unified moment magnitude $\mathrm{M}_{\mathrm{w}}$. In case both the magnitudes have measurement 
errors, due to saturation or otherwise, the use of least-squares linear regression procedure may yield wrong results. In such a situation, it is appropriate to use General Orthogonal Regression (GOR) procedure, which takes into account the errors on both the magnitudes (Joshi and Sharma 2008; Thingbaijam et al. 2008; Ristau 2009; Wason et al. 2012; Das et al. 2013). As the derivation of GOR relation involves the orthogonal projection of observed magnitude data pairs on the GOR line, the computation of estimates of a preferred magnitude type using these GOR relations in their existing form is liable to introduce some error. Most of PSHA studies are based on either heterogeneous or inappropriately homogenous earthquake catalog. Therefore, it is important to estimate seismicity parameters from an accurate earthquake catalog. To achieve this, global relations based on an improved technique towards moment magnitude have been used to convert surface wave magnitude to moment magnitude and equations are given below (Wason et al. 2012).

$$
\begin{array}{ll}
M_{w}=0.646 m_{s, \mathrm{obs}}+2.197 & 3.1 \leq m_{s} \leq 6.1 \\
M_{w}-1.005 m_{s, \mathrm{obs}}-0.0062 & 6.2 \leq m_{s} \leq 8.4
\end{array}
$$

Regional relations for such a conversion have been proposed for various parts of the world, e.g., for Japan (Tanaka et al. 2004; Sarlis et al. 2013; Varotsos et al. 2013) and for Greece (Sarlis et al. 2008). In particular, the regional relations for Himalayan region for conversion of body wave magnitude to moment magnitude (Das et al. 2013) has been used and the equation is given below

$$
M_{w}=1.17 m_{b, \mathrm{obs}}-0.74
$$

Ristau et al. (2005) reported that for continental crust events $M_{w}=M_{l}$ for earthquakes with $M_{l} \geq$ 3.8 from these observations $M_{l}$ is assumed almost equivalent to $M_{w}$ in this study. In order to convert historical earthquakes with intensity values only, the empirical relation $M_{w}=0.762 * \mathrm{MMI}+0.865$ (Das et al. 2012a, b) has been used to estimate magnitude from intensity data. This exercise resulted in the preparation of the catalog for the study region, which consists of 3015 earthquakes.

The declustering involves removal of dependant events represented by foreshocks and aftershocks from the earthquake catalog. Since PSHA is based on the assumption that seismicity follows Poisson process, it is essential to remove any non-Poissonian behaviour from earthquake catalog. For this study, Gardner and Knopoff (1974) approach has been used considering specified timespace windows. Declustering eliminated $25 \%$ events from the catalog.

\section{Estimation of seismic hazard parameters}

Magnitudes of completeness $\left(\mathrm{M}_{\mathrm{c}}\right)$, GutenbergRichter (G-R) recurrence parameter ( $b$ and $a$ ) values have been estimated for each seismogenic zone from the homogenized earthquake catalog. The G-R relation (Gutenberg and Richter 1944) is the relation between logarithm of the annual rate of exceedance versus earthquake magnitude and expressed as:

$$
\log \lambda_{m}=a-b m
$$

where $\lambda_{m}$ is the mean annual rate of exceedance of magnitude $m, a$ is the general level earthquake activity in a given area during the study period and depends on seismicity of the region, $b$ the slope describes the relative likelihood of large to small earthquakes.

Due to the installation of WWSSN and other networks in 1960s, quality and quantity of
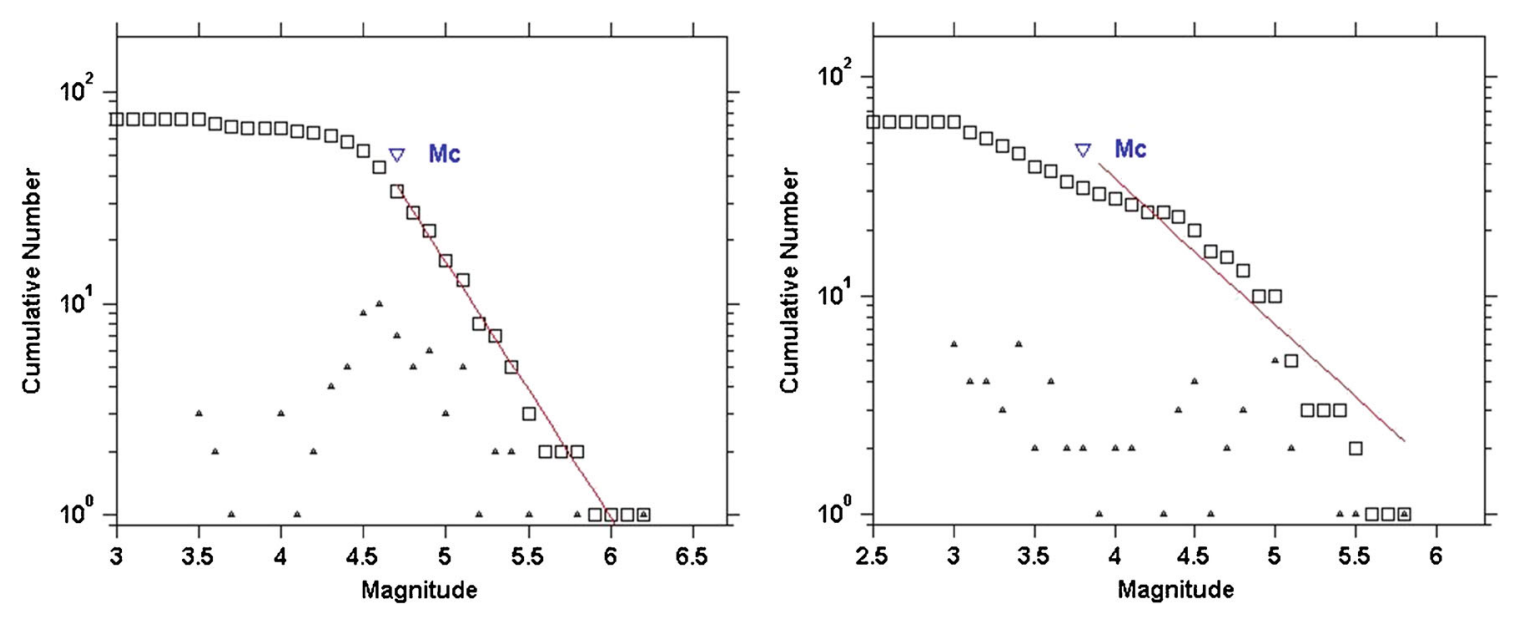

Figure 3. Frequency-magnitude relation (a) zone 10 and (b) zone 18. 
seismological data greatly improved. Hence, only instrumental earthquake catalog (after 1963) has been used to estimate seismic hazard parameters. The seismic hazard parameters are computed using Entire Magnitude Range Method (EMR) modified by Woessner and Wiemer (2005). This method is stable under most conditions and provides a comprehensive seismicity model. In seismogenic zones 8, 12, and 14, the EMR is not workable due to less earthquake events, for these zones Maximum Curvature method is used, though it slightly underestimates the magnitude of completeness (Woessner and Wiemer 2005). In the present study, ZMAP (Wiemer and Wyss 2001) software has been used to compute seismic hazard parameters.

Figure 3 shows frequency-magnitude relation for source zone 10 and 18 respectively, magnitude of completeness $=4.7$ for source zone 10 and 3.8 for source zone 18 . The seismic hazard parameters for each source zone have been obtained from cata$\log$ for the period 1964-2011, as shown in table 1 . It is concluded from the table that the $\mathrm{M}_{\mathrm{c}}$ value valid for the entire NW and central Himalaya region can be considered to be 4.7 for the catalog period 1964-2011.

Table 1. Seismic hazard parameters considering earthquake data after 1963.

\begin{tabular}{|c|c|c|c|c|c|c|c|c|}
\hline Z & $\mathrm{M}_{\mathrm{c}}$ & $\mathrm{a}$ & $\mathrm{b}$ & $\beta=2.303 * b$ & b error & beta coeff & $\lambda_{m}$ & $\begin{array}{l}\text { R.P for } \\
\text { Mag } 6\end{array}$ \\
\hline 1 & 4.1 & 3.45 & 0.79 & 1.82 & 0.23 & 0.53 & 1.20 & 9.55 \\
\hline 2 & 4.0 & 2.76 & 0.70 & 1.61 & 0.04 & 0.09 & 0.91 & 27.54 \\
\hline 3 & 4.0 & 3.36 & 0.88 & 2.03 & 0.50 & 1.15 & 0.69 & 83.18 \\
\hline 4 & 4.1 & 3.40 & 0.85 & 1.96 & 0.04 & 0.09 & 0.82 & 50.12 \\
\hline 5 & 4.0 & 3.61 & 0.97 & 2.23 & 0.08 & 0.18 & 0.54 & 162.18 \\
\hline 6 & 4.4 & 6.08 & 1.33 & 3.06 & 0.03 & 0.07 & 1.69 & 79.43 \\
\hline 7 & 4.2 & 4.58 & 1.10 & 2.53 & 0.04 & 0.09 & 0.91 & 104.71 \\
\hline 8 & 3.9 & 3.41 & 0.98 & 2.26 & 0.09 & 0.21 & 0.39 & 295.12 \\
\hline 9 & 4.0 & 3.17 & 0.78 & 1.80 & 0.06 & 0.14 & 1.12 & 32.36 \\
\hline 10 & 4.7 & 5.58 & 1.21 & 2.79 & 0.40 & 0.92 & 0.78 & 47.86 \\
\hline 11 & 4.3 & 4.60 & 1.11 & 2.56 & 0.20 & 0.46 & 0.67 & 114.82 \\
\hline 12 & 4.1 & 3.27 & 0.79 & 1.82 & 0.10 & 0.23 & 1.07 & 29.51 \\
\hline 13 & 4.1 & 3.32 & 0.80 & 1.84 & 0.03 & 0.07 & 1.10 & 30.20 \\
\hline 14 & 3.9 & 1.93 & 0.84 & 1.93 & 0.00 & 0.00 & 0.05 & 1288.25 \\
\hline 15 & 4.4 & 4.43 & 0.98 & 2.26 & 0.03 & 0.07 & 1.31 & 28.18 \\
\hline 16 & 4.4 & 4.38 & 0.92 & 2.12 & 0.22 & 0.51 & 2.15 & 13.80 \\
\hline 17 & 4.4 & 4.23 & 0.91 & 2.10 & 0.15 & 0.35 & 1.68 & 16.98 \\
\hline 18 & 3.8 & 2.52 & 0.67 & 1.54 & 0.50 & 1.15 & 0.94 & 31.62 \\
\hline 19 & 4.3 & 4.44 & 1.06 & 2.44 & 0.27 & 0.62 & 0.76 & 83.18 \\
\hline 20 & 4.6 & 5.54 & 1.14 & 2.63 & 0.12 & 0.28 & 1.98 & 19.95 \\
\hline 21 & 4.5 & 5.58 & 1.26 & 2.90 & 0.18 & 0.41 & 0.81 & 95.50 \\
\hline 22 & 4.5 & 6.21 & 1.33 & 3.06 & 0.13 & 0.30 & 1.68 & 58.88 \\
\hline
\end{tabular}

Table 2. Seismogenic zone and corresponding observed and maximum magnitudes.

\begin{tabular}{lccccc}
\hline $\begin{array}{l}\text { Seismogenic } \\
\text { zone }\end{array}$ & $M_{\max }^{\text {obs }}$ & $M_{\max }$ & $\begin{array}{c}\text { Seismogenic } \\
\text { zone }\end{array}$ & $M_{\max }^{\text {obs }}$ & $M_{\max }$ \\
\hline 1 & 7.7 & $8.0 \pm 0.20$ & 12 & 6.7 & $7.45 \pm 0.07$ \\
2 & 7.6 & $8.1 \pm 0.36$ & 13 & 6.8 & $7.49 \pm 0.58$ \\
3 & 6.5 & $7.19 \pm 0.58$ & 14 & 5.6 & $6.2 \pm 0.62$ \\
4 & 7.5 & $8.0 \pm 0.52$ & 15 & 6.5 & $7.0 \pm 0.45$ \\
5 & 7.1 & $7.88 \pm 0.76$ & 16 & 7.5 & $8.1 \pm 0.46$ \\
6 & 7.3 & $7.90 \pm 0.42$ & 17 & 6.5 & $7.1 \pm 0.63$ \\
7 & 8.0 & $8.37 \pm 0.30$ & 18 & 6.0 & $6.5 \pm 0.52$ \\
8 & 5.5 & $6.0 \pm 0.72$ & 19 & 7.0 & $7.75 \pm 0.86$ \\
9 & 6.5 & $7.1 \pm 0.51$ & 20 & 8.3 & $8.5 \pm 0.46$ \\
10 & 6.3 & $6.9 \pm 0.35$ & 21 & 6.7 & $7.3 \pm 0.58$ \\
11 & 5.9 & $6.5 \pm 0.53$ & 22 & 7.1 & $7.5 \pm 0.36$ \\
\hline
\end{tabular}




\subsection{Maximum magnitude $\left(m_{\max }\right)$}

Maximum magnitude is defined as the upper limit of magnitude for a given seismogenic zone or entire region. As $m_{\max }$ reflects maximum potential of strain released in the scenario earthquake, it plays vital role in probabilistic seismic hazard assessment. For the present study, the non-parametric Gaussian (N-P-G) based estimator equation given by Kijko (2004) is used. Kijko's $m_{\max }$ toolbox written in MATLAB has been used for the computation of maximum magnitude, both historical and instrumental seismicity data has been used to determine $m_{\max }$ (table 2).

\section{Ground motion prediction equations and seismic hazard estimation}

One of the most important aspects in the seismic hazard analysis is the selection of proper ground motion attenuation relationship. The accuracy of these relationships is based on the data, function taken, and methodology used to derive it. As it directly influences the estimation of strong ground motion, it plays a vital role in hazard estimation. Generally, region specific attenuation relationships are preferred for estimation of ground motion; in the absence of these, global relations can be used with similar conditions. As the Himalayas are characterised by shallow crustal earthquakes, the ground motion prediction equation is selected according to the assessment carried out by Nath and Thingbaijam (2011). Several attenuation relationships have been developed considering worldwide database for the shallow crustal earthquakes, which mainly includes Zhao et al. (2006), Boore and Atkinson (2008), Campbell and Bozorgnia (2008), Chiou and Youngs (2008), Akkar and Bommer (2010) and these have been used to estimate PGA. Depth to shear-wave velocity $V_{s}=$ $1.0 \mathrm{~km} / \mathrm{s}\left(Z_{1.0}\right)$ is estimated using the relation between $Z_{1.0}$ and $V_{S 30}$ given by (Chiou and Youngs 2008) while depth to $V_{S}=2.5 \mathrm{~km}\left(Z_{2.5}\right)$ is assigned $2 \mathrm{~km}$ following Boore and Atkinson (2008). In the present work, shear wave velocity $\left(V_{s 30}\right)$ is taken as $1300 \mathrm{~m} / \mathrm{s}$, which means peak ground motion is computed at bed rock level.

The methodology developed by Cornell (1968) for PSHA is applied for the estimation of seismic hazard in terms of PGA for $10 \%$ and $2 \%$ probability of exceedance in 50 years. Logic tree method is used in the computation at each site to incorporate multiple ground motion prediction equations. In this method, the annual rate of ground motion exceeding a specified value is computed to account for different return periods of the hazard. The probability of exceeding a particular value, $y^{*}$, of a ground motion parameter, $Y$, is calculated for one possible earthquake at one possible source location and then multiplied by the probability that the particular magnitude earthquake would occur at that particular location (Kramer 2003). The process is repeated for all possible magnitudes and locations. The probability of exccedance is given as:

$$
\begin{aligned}
P & {\left[Y>y^{*}\right] } \\
& =\iint P\left[Y>y^{*} \mid m, r\right] f_{M}(m) f_{R}(r) d m d r
\end{aligned}
$$

where $P\left[Y>y^{*}\right]$ is obtained from predictive relationship and $f_{M}(m)$ and $f_{R}(r)$ are the probability density functions for magnitude and distance, respectively.

If the site of interest is in a region of $N_{s}$ potential earthquake sources, each of which has an average rate of threshold magnitude exceedance, $\left[v_{i}=\right.$ $\left.\exp \left(v_{i}-\beta_{i} m_{0}\right)\right]$, the total average exceedance rate for the region will be given by:

$$
\begin{aligned}
\lambda_{y^{*}}= & \sum_{i=1}^{N_{S}} v_{i} \\
& \times \iint P\left[Y>y^{*} \mid m, r\right] f_{M i}(m) f_{R i}(r) d m d r
\end{aligned}
$$

The parameters appearing in the above equations are complicated and integrals cannot be evaluated analytically to estimate realistic PSHAs. To simplify, magnitude is divided into ranges and distance into number of different segments to analyze separately. The probabilistic seismic hazard estimation software CRISIS-2012 developed by Ordaz et al. (2012) has been used.

\section{Result and discussion}

For estimating PSHA, the study area of NW and central Himalayas and the surrounding region between latitude $27^{\circ} 2^{\prime}-35^{\circ} \mathrm{N}$ and longitude $72^{\circ}-$ $88^{\circ} \mathrm{E}$ is divided into small grids of size $0.2^{\circ} \times 0.2^{\circ}$. In this method, parameters such as $a, b, m_{c}, m_{\max }$ and attenuation models are the input parameters in the CRISIS program and PGA and PSA are the output. PGA has been computed at the centre of all the grid points for return period of 475 years and 2500 years (i.e., $10 \%$ and $2 \%$ probability of exceedance in 50 years) and ground motion distribution is shown in the form of zones considering varying $b$-value for each zone.

For $10 \%$ probability of exceedance in 50 years (return period of 475 years), the PGA values vary from 0.06 to $0.36 \mathrm{~g}$ for NW and central Himalayan region (figure 4). In the western part of Nepal, PGA varies from 0.29 to $0.36 \mathrm{~g}$. PGA value of $0.22-0.26 \mathrm{~g}$ is observed around Kaurik fault system, western part of Uttarakhand, eastern part of Nepal, and a small portion of Jammu. For major parts of the state of Himachal Pradesh and central Nepal, the PGA varies from 0.12 to $0.16 \mathrm{~g}$. In the remaining 


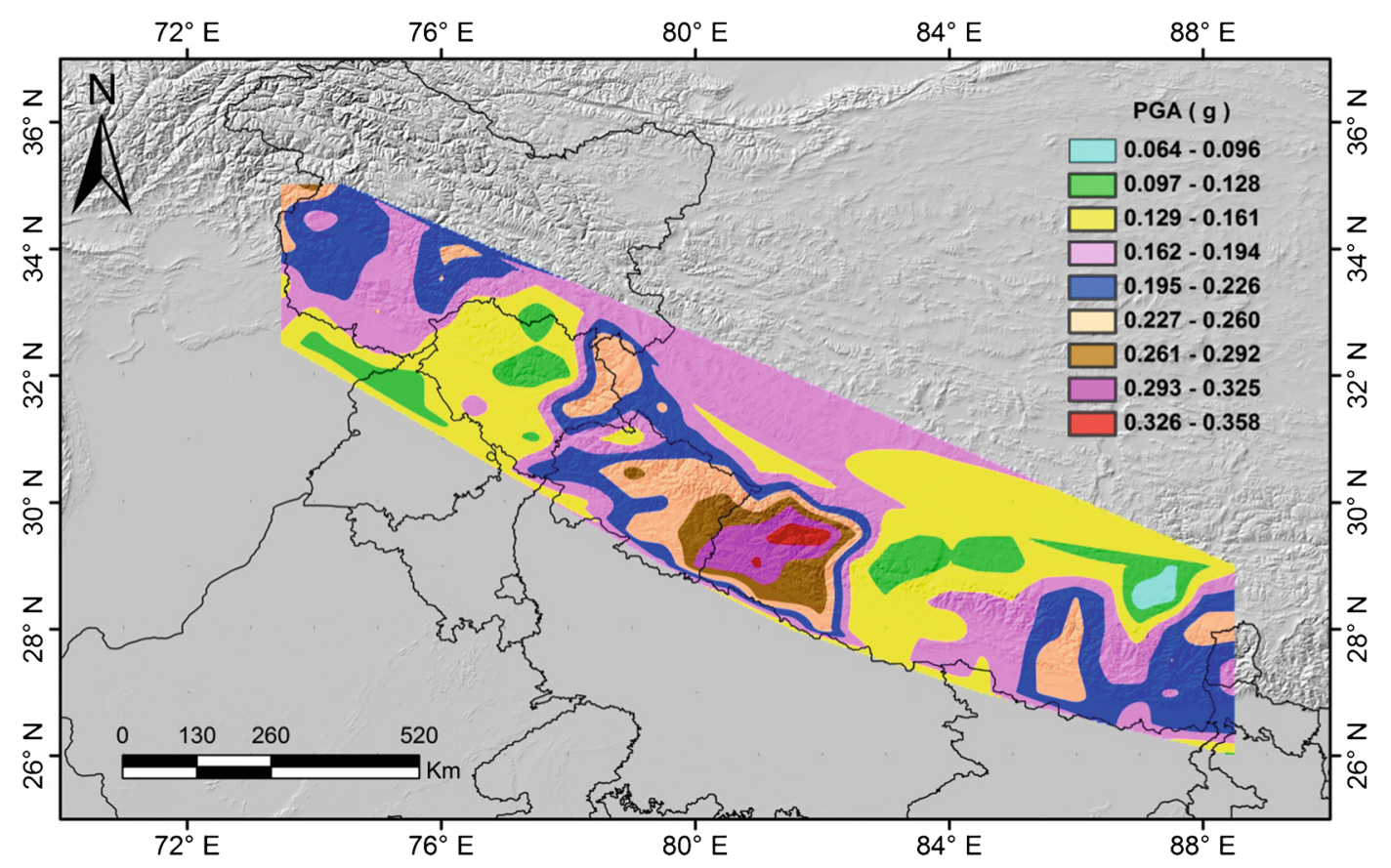

Figure 4. Peak ground acceleration for $10 \%$ probability of exceedance in 50 years.

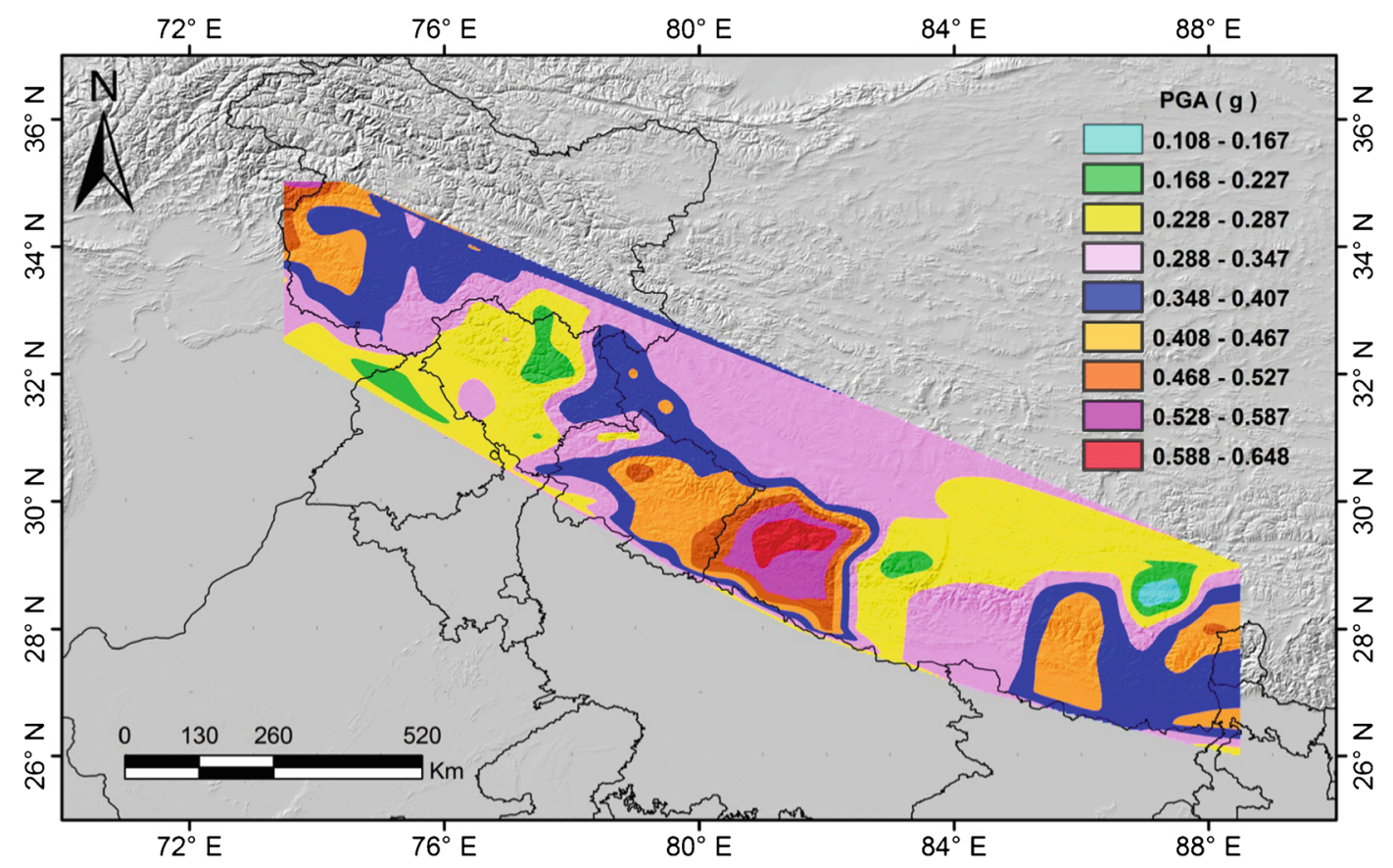

Figure 5. Peak ground acceleration for $2 \%$ probability of exceedance in 50 years.

portion of NW and central Himalaya PGA varies from 0.19 to $0.22 \mathrm{~g}$.

However, for $2 \%$ probability of exceedance in 50 years (return period of 2500 years), the PGA varies from 0.11 to $0.65 \mathrm{~g}$ considering varying $b$ values (figure 5). Highest PGA is observed in the western part of Nepal and varies from 0.52 to $0.65 \mathrm{~g}$. PGA value of $0.34-0.40 \mathrm{~g}$ is observed around
Kaurik fault system and PGA values of $0.46-0.52 \mathrm{~g}$ are observed around western part of Uttarakhand and eastern part of Nepal. For major parts of the state of Himachal Pradesh and central Nepal, the PGA varies from 0.22 to $0.28 \mathrm{~g}$.

Table 3 shows the comparison of PGA at $10 \%$ probability of exceedance in $50 \mathrm{yr}$ from different studies in the NW and central Himalaya. In the 
Table 3. Estimated peak ground acceleration with $10 \%$ probability of exceedance in 50 years from different studies.

\begin{tabular}{lcc}
\hline $\begin{array}{l}\text { Research carried out by } \\
\text { author/agency }\end{array}$ & $\begin{array}{c}\text { Type of } \\
\text { study }\end{array}$ & $\begin{array}{c}\text { Max PGA } \\
(\mathrm{g})\end{array}$ \\
\hline Khattri et al. $(1984)$ & PSHA & 0.70 \\
Bhatia et al. $(1999)$ & PSHA & 0.40 \\
Parvez et al. $(2003)$ & DSHA & 0.60 \\
Mahajan et al. $(2010)$ & PSHA & 0.75 \\
NDMA, GOI $(2011)$ & PSHA & 0.18 \\
Nath and Thingbaijam (2012) & PSHA & 0.60 \\
\hline
\end{tabular}

northwestern Himalaya, Mahajan et al. (2010) estimated the maximum PGA as $0.75 \mathrm{~g}$. Khattri et al. (1984) estimated expected PGA at bed rock range from 0.4 to $0.7 \mathrm{~g}$ with $10 \%$ probability of exceedance in 50 years and used MM1 (Modified Mercalli intensity) vs. distance relations. Bhatia et al. (1999) estimated expected PGA for the Himalayan region between 0.10 and $0.40 \mathrm{~g}$ with $10 \%$ probability of exceedance in 50 years using Joyner and Boore Attenuation equation. These values were obtained under Global Seismic Hazard Assessment Programme (GSHAP). Parvez et al. (2003) conducted DSHA of India and adjoining region and observed wide variation in Design Ground Acceleration (DGA). National Disaster Management Authority (NDMA 2011), Government of India estimated maximum PGA of $0.18 \mathrm{~g}$ at return period of 475 in the same region. All the above-discussed investigations are either based on inappropriately homogenized earthquake catalog or heterogeneous catalogs with old attenuation equations. In this study, an improved homogenization technique for magnitude conversion has been used with updated attenuation equations for estimation of strong ground motion.

\section{Conclusions}

The present study delivers a new generation PSHA map for NW and central Himalaya. An attempt has been made to improve the hazard assessment with incorporation of improved magnitude conversion techniques and updated attenuation relations. The hazard distribution has been performed on grid spaceing of 0.2 degree. For $10 \%$ probability of exceedance in 50 years (return period of 475 years), the PGA values vary from 0.06 to $0.36 \mathrm{~g}$ and $2 \%$ probability of exceedance in 50 years (return period of 2500 years), the PGA varies from 0.11 to $0.65 \mathrm{~g}$ for the study area. The present results are higher than the suggested ground motion for zone-V of seismic zonation map of India but matches with the results of GSHAP.

\section{Acknowledgements}

Earthquake data from India Meteorological Department, India, US Geological Survey, USA and International Seismological Centre, On-line Bulletin, United Kingdom catalogs have been used in this study and the authors remain grateful for their support. The first author is thankful to MHRD, Govt. of India for PhD Fellowship.

\section{References}

Akkar S and Bommer J J 2010 Empirical equations for the prediction of PGA, PGV, and spectral accelerations in Europe, the Mediterranean region, and the Middle East; Seismol. Res. Lett. 81 195-206.

Bhatia S C, Kumar R M and Gupta H K 1999 A probabilistic seismic hazard map of India and adjoining regions; Ann. Geofis. 42(6) 1153-1164.

BIS Code 18932002 Earthquake hazard zoning map of India; www.bis.org.in.

Boore D M and Atkinson G M 2008 Ground-motion prediction equations for the average horizontal component of PGA, PGV, and 5\% damped PSA at spectral periods between 0.01s and 10.0s; Earthquake Spectra 24 99-138.

Campbell K W and Bozorgnia Y 2008 NGA ground motion model for geometric mean horizontal component of PGA, PGV, PGD and 5\% damped linear elastic response spectra for periods ranging from 0.01 to $10 \mathrm{~s}$; Earthquake Spectra 24(1) 139-171.

Chiou B S J and Youngs R R 2008 Empirical ground motion model for the average horizontal component of peak acceleration and pseudo-spectral acceleration for spectral periods of 0.01 to 10 seconds; Earthquake Spectra 24(S1) $173-216$.

Cornell C A 1968 Engineering seismic risk analysis; Bull. Seismol. Soc. Am. 58 1583-1606.

Das R, Wason H R and Sharma M L 2012a Magnitude conversion to unified moment magnitude using orthogonal regression relation; J. Asian Earth Sci. 50(2) $44-51$.

Das R, Wason H R and Sharma M L 2012b Temporal and spatial variations in the magnitude of completeness for homogenized moment magnitude catalog for northeast India; J. Earth Syst. Sci. 121(1) 19-28.

Das R, Wason H R and Sharma M L 2013 General orthogonal regression relation between body and moment magnitudes; Seismol. Res. Lett. 84(2) 219-224.

Development of probabilistic seismic hazard map of India 2011 Technical Report, National Disaster Management Authority (NDMA), Government of India, New Delhi.

Gansser A 1977 The great suture zone between Himalaya and Tibet: A preliminary note; AccSci Terre Himalayas CNRS 268 181-192.

Gardner J K and Knopoff L 1974 Is the sequence of earthquakes in southern California, with aftershocks removed, Poissonian? Bull. Seismol. Soc. Am. 64 1363-1367.

GSI 2000 Seismotectonic Atlas of India and its Environs; Geological Survey of India.

Gupta I D 2006 Delineation of probable seismic sources in india and neighbourhood by a comprehensive analysis of seismotectonic characteristics of the region; Soil Dynam. Earthquake Eng. 267 766-790.

Gutenberg B and Richter C F 1944 Frequency of Earthquakes in California; Bull. Seismol. Soc. Am. 34(4) 1985-1988. 
Iyengar R N, Sharma D and Siddiqui J M 1999 Earthquake history of India in medieval times; Ind. J. Hist. Sci. 34(3) 181-237.

Joshi G C and Sharma M L 2008 Uncertainties in the 679 estimation of $M_{\max }$; J. Earth Syst. Sci. 117 671-682.

Khattri K N, Rogers A M, Perkins D M and Algermissen S T 1984 A seismic hazard map of India and adjacent area; Tectonophys. 108 93-134.

Kijko A 2004 Estimation of the maximum earthquake 681 magnitude, $M_{\max }$; Pure Appl. Geophys. 161 1655-1681.

Kramer S L 2003 Geotechnical Earthquake Engineering, Prentice Hall International Series, Pearson Education, Delhi, Chapter 4.

Mahajan A K, Thakur V C, Sharma M L and Chauhan M 2010 Probabilistic seismic hazard map of NW Himalaya and its adjoining area, India; Nat. Hazards 53 443-457.

Nath S K and Thingbaijam K K S 2012 Probabilistic seismic hazard assessment of India; Seismol. Res. Lett. 83 135-149.

Nath S K and Thingbaijam K K S 2011 Peak ground motion predictions in India: An appraisal for rock sites; J. Seismol. 15 295-315.

Oldham T 1883 A catalog of Indian earthquakes from the earliest times to the end of 1869 AD; Geol. Surv. India Memoir, XIX Part-3.

Ordaz M, Aguilar A and Arboleda J 2003 CRISIS 2003: Program for computing seismic hazard, Ver. 3.01.

Ordaz M, Martinelli F, Aguitar A, Arboleda J, Meletti C and Amico V D 2012 CRISIS 2007: Program for computing seismic hazard, Ver. 4.4, Instituto de Ingenieria, UNAM, Mexico.

Parvez I A, Vaccari F and Panza G F 2003 A deterministic seismic hazard map of India and adjacent areas; Geophys. J. Int. 155(2) 489-508.

Patil N S, Das J D, Kumar A, Rout M M and Das R 2014 Probabilistic seismic hazard assessment of Himachal Pradesh and adjoining regions; J. Earth Syst. Sci. 123(1) 49-62.

Ristau J 2009 Comparison of magnitude estimates for New Zealand earthquakes: Moment magnitude, local magnitude, and teleseismic body-wave magnitude; Bull. Seismol. Soc. Am. 99 1841-1852.
Ristau J, Rogers G C and Cassidy J F 2005 Moment magnitude-local magnitude calibration for earthquakes in western Canada; Bull. Seismol. Soc. Am. 95 19942000.

Sarlis N V, Skordas E S, Lazaridou M S and Varotsos P A 2008 Investigation of seismicity after the initiation of a seismic electric signal activity until the main shock; Proc. Jpn. Acad. Ser. B 84 331-343.

Sarlis N V, Skordas E S, Varotsos P A, Nagao T, Kamogawa M, Tanaka H and Uyeda S 2013 Minimum of the orderparameter fluctuations of seismicity before major earthquakes in Japan; Proc. Natl. Acad. Sci. USA 110(34) 13,734-13,738.

Tanaka H, Varotsos P A, Sarlis N V and Skordas E S 2004 A plausible universal behavior of earthquakes in the natural time-domain; Proc. Jpn. Acad. Ser. A 80 $283-289$.

Thingbaijam K K S, Nath S K, Yadav A, Raj A, Walling M Y and Mohanty W K 2008 Recent seismicity in northeast India and its adjoining region; J. Seismol. 12 107-123.

Valdiya K S 1980 Geology of Kumaun Lesser Himalaya; Wadia Institute of Himalayan Geology, Dehradun, pp. 290-291.

Varotsos P A, Sarlis N V, Skordas E S and Lazaridou M S 2013 Seismic electric signals: An additional fact showing their physical interconnection with seismicity; Tectonophys. 589 116-125.

Wason H R, Das R and Sharma M L 2012 Magnitude conversion problem using general orthogonal regression; Geophys. J. Int. 190(2) 1091-1096.

Wiemer S and Wyss M 2001 ZMAP: A Tool for Analyses of Seismicity Patterns. A cookbook; 57p.

Woessner J and Wiemer S 2005 Assessing the quality of earthquakes catalogs: Estimating the magnitude of completeness and its uncertainty; Bull. Seismol. Soc. Am. 95(2) 684-698.

Zhao J X, Zhang J, Asano A, Ohno Y, Oouchi T, Takahashi T, Ogawa H, Irikura K, Thio H K, Somerville P G, Fukushima Y and Fukushima Y 2006 Attenuation relations of strong ground motion in Japan using site classification based on predominant period; Bull. Seismol. Soc. Am. 96(3) 898-913. 